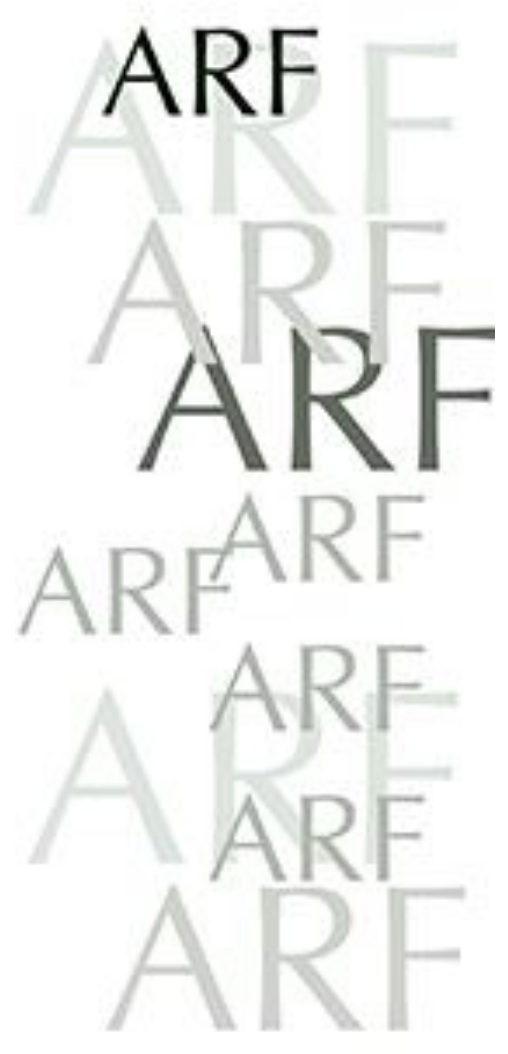

\title{
Learning from Precedent
}

\author{
The (ir)reproducibility of home
}

\author{
Ranald Lawrence \\ University of Liverpool \\ ranald.lawrence@liverpool.ac.uk
}

\begin{abstract}
This paper argues that precedent should play a fundamental role in the development of sustainable homes. It will describe how the design of two energy efficient family homes in Winchester, England, adopt a distinctive approach to environmental precedent.
\end{abstract}

The modern house is substantially a product of numerical calculation, such as the modelling of performance data and cost-benefit analysis. Construction (materials, u-values) and processes (energy use, assembly, airtightness) are quantified and assessed to ensure they achieve design objectives based on recognised standards of performance (Energy Performance Certificate: A; Code for Sustainable Homes: level 4).

However this technical analysis alone cannot inform the initial creative idea. The design of these houses was informed by intuitive reference to a range of diverse precedents, including the work of Alvar Aalto, Sverre Fehn, Robert Venturi and Roelof Uytenbogaardt.

The asymmetric roofs of Aalto's Housing for ex-service men in Tampere (1941) define thresholds to front and side doors, and a sheltered private space to the back overlooking the garden. Fehn's Villa Norrköping (1964) was designed around circadian rhythms, with day and night-time spaces defined by glazed corners ('eyes') and alcoves, animated by daylight and shadow. Venturi's Mother's House (1964) symbolises in its idiosyncratic form and modest material treatment the pragmatic and egalitarian promise of a home and identity of one's own. House Uytenbogaardt (1993) exploits solar orientation and the topography of its location to the utmost, framing views of the horizon and sunsets over the ocean. The house is part fortified tower house, part bespoke wooden cabinet, responding to the unique atmosphere and light of the Western Cape coastline.

This paper will describe how these two subtly different Winchester houses borrow from each of these examples to reconcile technical requirements with the poetic possibilities inherent in imagining other environments, informed by the specific climate and conditions of the site.

Keywords: precedent, housing design, environment, technics, poetics 


\section{Introduction}

This article seeks to explain the significance of the role of precedent in environmental design, with reference to the author's own designs for two sustainable homes in Winchester, UK. In a previous paper authored with Hawkes, the author argued that precedent in architecture offers a dual role:

a) Reference to previous examples that are known to work well provide a degree of security in the production of new buildings.

b) Precedents embody principles from which development and innovation may proceed.

The paper begins by theorising how the relationship between a building and its climate, or inside and outside, is central to any architectural project, with reference to the work of Kenneth Frampton and Dean Hawkes, amongst others. It goes on to question the manner in which the contemporary discourse of sustainability has prioritised quantitative assessment at the expense of qualitative considerations, and how as a result the role of precedent has been overlooked.

In the following section four precedents of houses are examined to identify the different ways in which their respective architects respond to different aspects of their local climates. The selection of the precedents is subjective - an act of intuition - informed by the author's own background, preferences and architectural knowledge. The houses are located in quite different contexts and climatic regions, and the connections between them can at first glance appear coincidental, or even inconsequential. Despite their geographical separation, however, the four homes share surprising similarities. The personal relationships between their architects is reflected in the individual approaches they have adopted to context and climate. The houses reflect how different bodies of knowledge and experience diffuse geographically and are appropriated and reinvented across time and space - demonstrating how precedent often acts most powerfully at a subliminal level.

Finally the paper describes how these four homes influenced the author's approach to the design of two similar but subtly different homes in Winchester. The influence of the precedents on the design of the Winchester houses is sometimes apparent, sometimes concealed. The paper describes how the author borrowed from these examples to reconcile the technical requirements that underpin 'sustainable design' in the early $21^{\text {st }}$ century in the UK, with the poetic possibilities inherent in imagining other environments, informed by the specific climate and conditions of a particular given site. 


\section{Theory}

In Architecture of the Well-Tempered Environment, Reyner Banham attempted to expand the field of architectural history beyond what he perceived to be the limitations of a focus solely on form and aesthetics. Banham argued that an historical understanding could illuminate the technical problems of the present, and that solutions to architectural problems could not be fashioned purely by the application of analytical processes. His study focused on the historical significance of the role of the environment in architecture, and the phenomenon by which improved lighting, heating, cooling and ventilation led to more demanding expectations on the part of building users. In the final chapter, Banham described the history of the modern movement until that point as either 'the final liberation of architecture from the ballast of structure, or its total subservience to the goads of mechanical service' (Banham 1969, 265).

\section{'Universal \\ bureaucracy reproduces and facilitates the domination of a global technology and the overall telos of this technology tends to be quantitative rather than qualitative in nature.'}

\section{Kenneth Frampton}

Reviewing the consequences a quarter of a century later, Kenneth Frampton observed that 'universal bureaucracy reproduces and facilitates the domination of a global technology and the overall telos of this technology tends to be quantitative rather than qualitative in nature' (Frampton 1995, 24). In Studies in Tectonic Culture Frampton proposed a recovery of the meaning, representation and symbolism of construction, in order to enrich a Modernist discourse that he perceived had for too long prioritised architectural form above all else. Taking the Greek translation of the Vitruvian trinity (topos, typos, and tectonic), Frampton made the case for a rehabilitation specifically of the tectonic:

I am not alluding to the mere revelation of constructional technique but rather to its expressive potential. Inasmuch as the tectonic amounts to a poetics of construction it is art, but in this respect the artistic dimension is neither figurative nor abstract.

(Frampton 1995, 2)

For Frampton, consideration of the tectonic was by definition tactile and corporeal, moving beyond conceptual signification into the physical and messy world of building, shaped by pragmatism and inexactitude (or degrees of tolerance). As 'the body reconstitutes the world through its tactile appropriation of reality' (Frampton 1995, 10), we must always be mindful that our primary understanding of architecture is achieved through sensory experience:

The philosophical alienation of the body from the mind has resulted in the absence of embodied experience from almost all contemporary theories of meaning in architecture. The overemphasis on signification and reference in architectural theory has led to a construal of meaning as an entirely conceptual phenomenon. Experience, as it relates to understanding, seems reduced to a matter of the visual registration of coded messages a function of the eye which might well rely on the printed page and dispense with the physical presence of architecture altogether. (Gartner 1990)

This emphasis on the visual at the expense of other sensory experiences has led to a situation where it is possible, for example, to reduce thermal sensation to a quantified standard, irrespective of time, weather or season. Dean Hawkes has sought to extend Frampton's argument to broader questions about the environment. Just as in Modernist discourse the tectonic was relegated to a purely functional role, Hawkes argues that the environment has come to be understood as a purely practical concern defined by metrics and standards (or technics at the expense of poetics):

Mechanical and electrical service systems reached a state of development at which they could replace all of the elements of the natural environment in buildings. At this moment... ...the historical 


\section{'Technics or techniques or technologies alone, however important their role, fail to touch the central point... the significant environmental propositions in architecture rest upon acts of imagination in which technics are brought to bear in the service of poetic ends.'}

\section{Dean Hawkes}

struggle of all buildings to connect inside to outside could be replaced by the flick of a switch.

(Hawkes 1995, 15)

In The Environmental Imagination, Hawkes reflects on this division when he states that 'technics or techniques or technologies alone, however important their role, fail to touch the central point... the significant environmental propositions in architecture rest upon acts of imagination in which technics are brought to bear in the service of poetic ends' (Hawkes 2008, vi). Central to this act of imagination is the relationship to the real world, or a given site. Frampton has argued that:

The worst enemy of modern architecture is the idea of space
considered solely in terms of its economic and technical exigencies
indifferent to the ideas of the site...
Through the concept of the site and the principle of settlement, the
environment becomes (on the contrary) the essence of
architectural production.
(Frampton 1995, 8)

This renewed focus on the symbiotic relationship between construction and site underpins Frampton's theory of 'critical regionalism', not as a modern description of the vernacular, but as a reunified response to place that builds upon the vernacular, not denying modern materials or technology but applying them authentically, recognising the continuity of regional characteristics and culture:

The term critical regionalism is not intended to denote the vernacular, as this was once spontaneously produced by the combined interaction of climate, culture, myth and craft, but rather to identify those recent regional "schools" whose aim has been to represent and serve, in a critical sense, the limited constituencies in which they are grounded.

(Frampton 1983, 148)

What Frampton understood as 'regional schools', Colin St. John Wilson took to be a 'resistance'. He traced a lineage of architects who had been working in the modern tradition without abandoning 'association, reference and symbolic form' (Wilson 1995, 30). Quoting Aalto's dictum that 'We cannot create new form where there is no new content', he commented:

If there is one working principle that is common to all of the architects of the Resistance, it is this. Purposive form is generated from the inside out. To seek to freeze the forms that develop out of such a mode into a canon is irrational; to impose that canon as a mould into which any content can then be shoe-horned is simply a contradiction in terms.

(Wilson 1995, 28)

Proponents of 'the International Style' sought to create universal forms, and a by-product of this was a liberation from the supposed constraints imposed by climate - an environmental turn inwards. These architects adopted what Banham termed an 'exclusive' strategy, divorced from the immediate context, as the conditions of site could not be relied upon across global geographies. In contrast, architects of Wilson's 'Other Tradition' always sought to root their buildings in a specific time and place (Hawkes 2008, 68). Rather than developing a universal manifesto, this approach relied on an intuitive understanding of local culture and context, best demonstrated by architects working in environments with which they were most familiar. This stands in stark contrast to what the historian John Summerson described as Modernism's 'preoccupation with the programme': 
The conceptions which arise from a preoccupation with the programme have got, at some point, to crystallize into a final form... but there is no common theoretical agreement as to what happens at that point... One may even be speaking of a missing architectural language.

(Summerson 1957)

In recent years, a consensus has developed that sustainability is a critical attribute through which all architecture should be assessed. However, contemporary definitions of sustainability often prioritise technical solutions, mirroring the divisive lines of Modernist programmatic discourse. Echoing Summerson, Susannah Hagan has argued that there is:

No compelling, immediately identifiable formal language on which to pin the cause. Different architects practising environmental design have different attitudes to technology, nature, materials, and performance.

(Hagan 2008, 25)

The argument of this paper is that this search for a formal 'language' misses the central point. A truly responsive architecture must balance technical appraisal with an authentic interpretation of its context. Standards and metrics have to be converted into a built form by a poetic (creative) act - the first mark of pen on paper - an imaginative leap of faith that occurs before any design iteration can be initiated.

This imaginative act cannot be undertaken with confidence without prior knowledge of the subject at hand. How have others attempted to solve the same problem in the past? In architecture this will be undertaken intentionally (or inadvertently) with reference to precedent. How should a building for this purpose be organised? What scale should it be? From what materials and using what methods should it be constructed? What adaptations should be made for comfort in a particular climate? The answers to these questions rely on knowledge of previous examples.

Any definition of sustainability will therefore be incomplete without reference to the role of precedent. This is perhaps best illustrated in the distinction between a house - a generic descriptor for a building that people live in - and a 'home' belonging to a particular person or family. A truly sustainable home will be specifically adapted to an individual or family's needs, with reference to its context. It is inadequate to simply copy a type-model cookie-cutter style, no matter its technical sufficiency. 


\section{Precedents}

\section{Housing for ex-service men, $61^{\circ} \mathrm{N}$}

Alvar Aalto (1941)

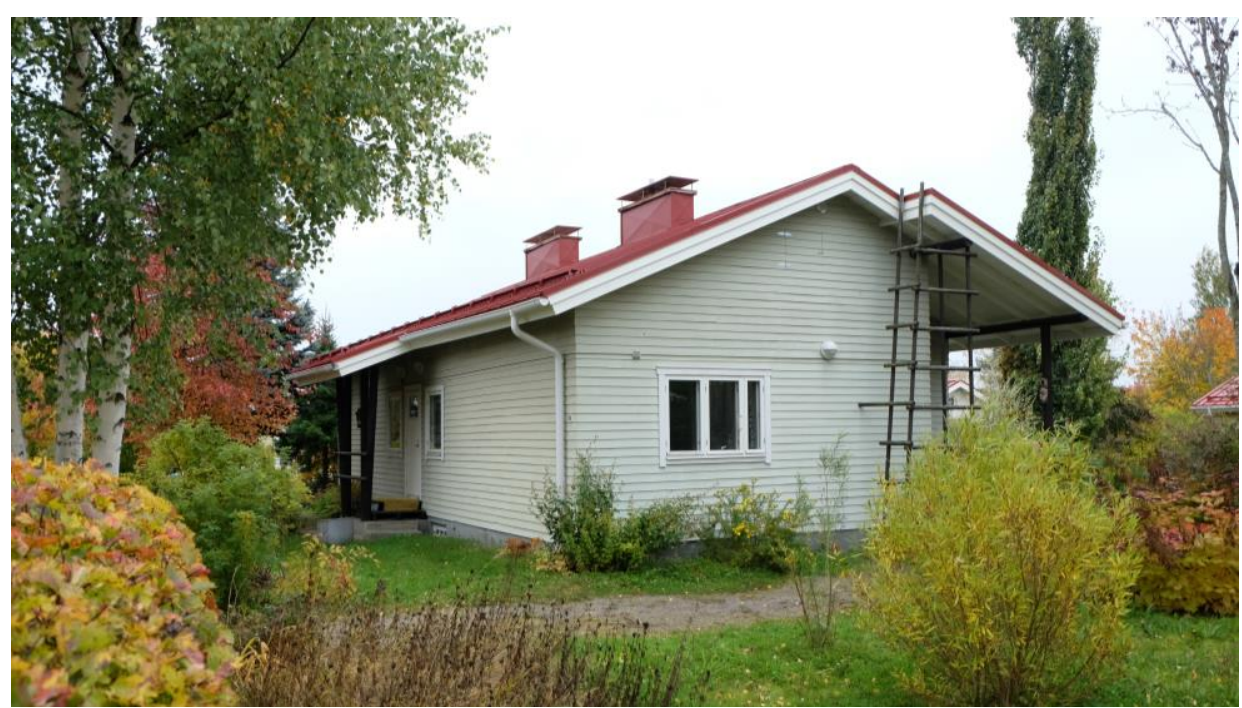

Figure 1. Housing for ex-service men, Alvar Aalto, 1941. View from Saviniementie. Author.

Aalto designed the Asevelikylä housing for ex-service men in Nekala, Tampere, following the winter war of 1939-40. Thirteen houses were constructed in total, with prefabricated timber parts manufactured by the A. Ahlström Company in Varkaus (Figure 1). This standardisation reflected the urgent need for reconstruction following the Soviet bombing of the city, though the Tampere Brothers-in-Arms Association, rather than the city government, funded the development and provided volunteer labour for construction (Jetsonen, Jetsonen, and Lahti 2011).

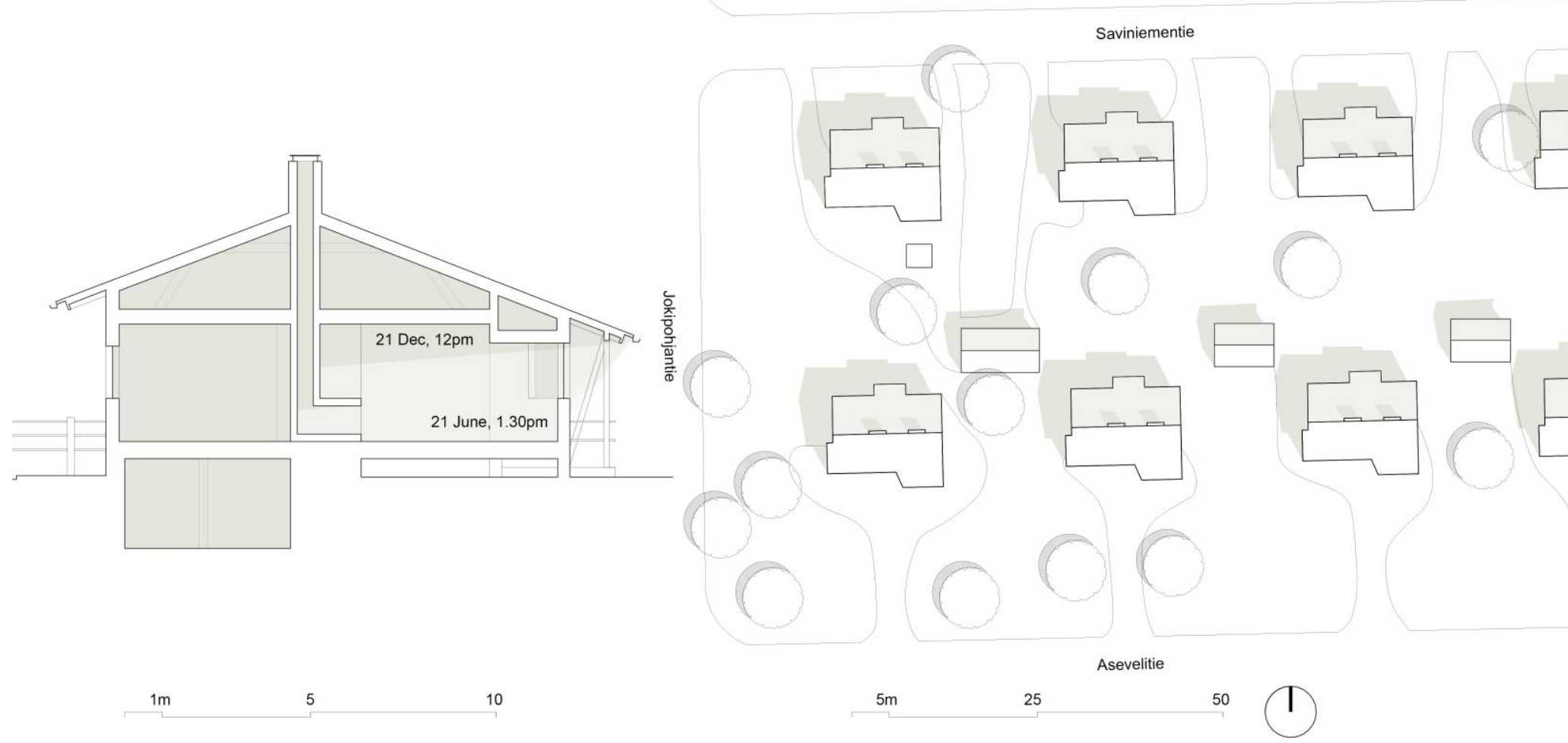

Figure 2. Housing for ex-service men, Alvar Aalto, 1941. Site plan and section. Drawings by Sam Beckwith Flint. 


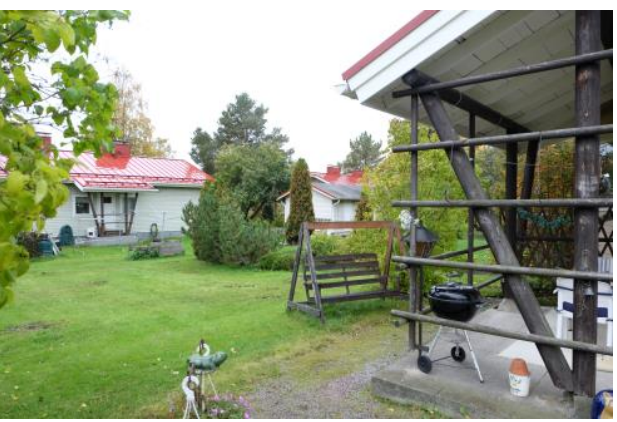

Figure 3. Housing for ex-service men, Alvar Aalto, 1941. The communal garden to the rear. Author.

At this time Aalto held a visiting professorship at MIT, where - conscious of the political sensitivities of the time - he sought to disassociate his work from the modern movement, as the aspirations and international reach of its central protagonists could be perceived by his hosts to be analogous to communism (Pelkonen 2009). Instead Aalto focused on the urgency of the housing shortage in Finland through the planning of new settlements reflecting the needs of established communities, inspired by the pragmatic regionalism of American theorists and urban planners such as Lewis Mumford. Reflecting on the problems of mass housing. Aalto wrote 'the purpose is not to aim at identical types, rather to aim at change and creative richness which in the ideal situation is to be compared with the inexhaustible gift for nuances possessed by nature' (Aalto 1941).

These principles of 'flexible standardisation' were demonstrated in Aalto's design for the 'forest town' at Sunila pulp mill, completed in 1937 (Schildt 1986, 266-67). Splayed terraces face south and follow the topography of the slope lending each residential unit individuality within the language of the whole.

While the Sunila development follows the pre-war Modernist language of white walls and flat terraces, the thirteen 'standard type' houses in Tampere, arranged in two rows with a communal garden in between, appear more rustic, with asymmetric roof pitches stepping in plan and defining thresholds to front and side doors, and sheltering terraces to the rear (Figure 2). The modest construction, reflecting the economic privations of the time, bely the sophistication of the design, with window bays jutting out from the plan to catch the afternoon sun and provide long views into the communal garden (Figure 3 ). The result is an altogether softer architectural language, rooted in the Finnish psyche, reflecting the importance of nature, and connection to outdoors in response to the uncertainties of a difficult political and economic climate.

Each house is slightly raised off the ground; a product of the timber construction that lends privacy to the bedrooms and living space while also ensuring the sun's warmth can penetrate the depth of the plan in winter. At first glance the houses appear identical, but closer examination reveals differentiation: in the relationship to the neighbouring streets to south and north; the informal landscape of the shared garden; and through each owner's appropriation of their trellised terraces and adjoining outdoor spaces, reflecting the individual personalities and patterns of life of their owners.

\section{Villa Norrköping, $59^{\circ} \mathrm{N}$}

\section{Sverre Fehn (1964)}

In 1920 Alvar Aalto travelled to Stockholm, hoping to gain employment in Asplund's office. While unsuccessful, he struck up a friendship with Apslund, and Aalto often instructed his assistants, including Arne Korsmo, to go and see Asplund's work. Korsmo went on to teach at the architecture school in Oslo, where he tutored Sverre Fehn, who graduated in the second cohort in 1949. Through Korsmo Fehn inherited Asplund and Aalto's sensitivity to the Nordic environment, and the importance of orientation in a land where the sun's role as a source of warmth and life is heightened.

Arne Korsmo was an influential figure in Fehn's work. Fehn later bought and lived for the rest of his life in Villa Damman, built by Korsmo following the Stockholm Exhibition of $1930 .{ }^{1}$ Fehn came into contact with CIAM through Jørn Utzon, Aldo Van Eyck and Alison and Peter Smithson, but could not afford to travel to the meetings himself. He was however awarded a scholarship to study in Paris under Jean Prouvé in 1953, where he would go and watch Le

\footnotetext{
${ }^{1}$ Korsmo also maintained a 40 year friendship with Louis Kahn, who he met by chance on the train to Rome in 1928. Kahn travelled through Sweden and Finland on the way to visit his grandmother in Estonia that year, and it is interesting to speculate which buildings he may have seen on the way (Fjeld and Fjeld 2019, 25, 42).
} 
Corbusier working in his studio when it was opened up to students in the evening. On returning to Oslo he started his own practice in 1954.

Villa Norrköping was designed in 1963-64, following the design of two pavilions in Brussels in 1958 and Venice in 1962, where Fehn demonstrated his environmental intuition experimenting with recreating overcast Nordic skies in other climates. At first glance Villa Norrköping has an ambivalent relationship to its context (Figure 4). It was designed in a competition for a standard house for a family of four, with an area of 150 square metres, but no prescribed site.

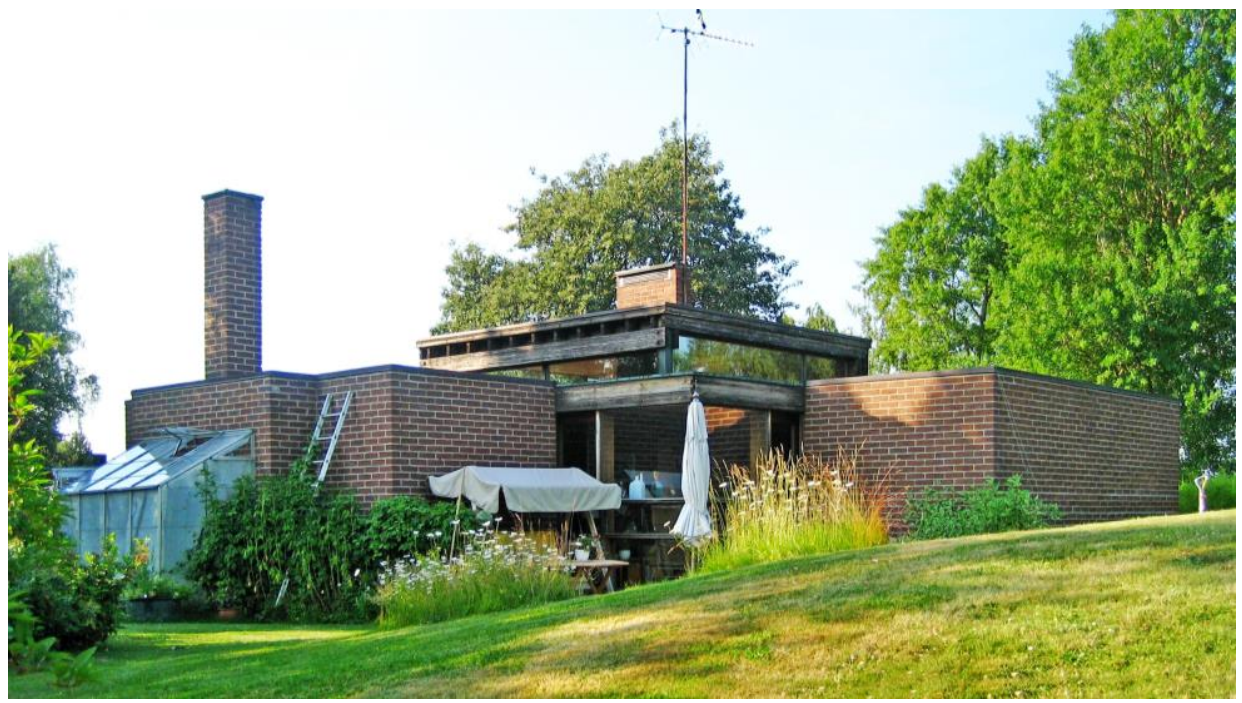

Figure 4. Villa Norrköping, Sverre Fehn, 1964. The view from the south.

Photography by Sebastian F. Licensed for reuse under creativecommons.org/licenses/by-sa/3.0.

The entrance faces north-west. A cruciform plan based on a 2.5 metre grid wraps around a toplit core, housing the kitchen and bathroom (Figure 5). Four glazed corners - the eyes - are recessed and open to the surrounding landscape. Four windowless alcoves form rooms in between the corners that are shrouded in shadow, denied any direct light (Papkovskaia 2011).

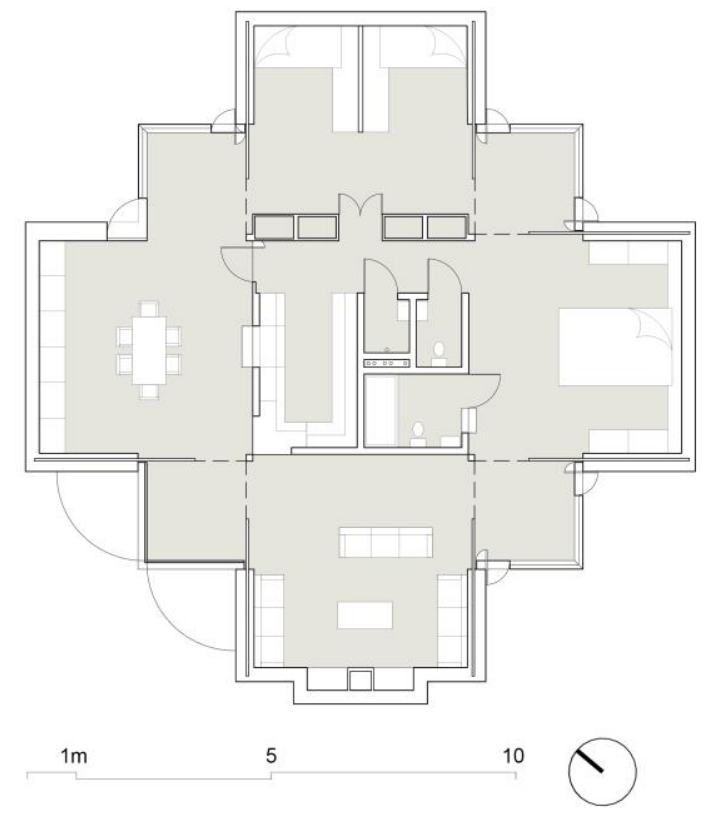

Figure 5. Villa Norrköping, Sverre Fehn, 1964. Plan and section.

Drawings by Sam Beckwith Flint.

The children's bedroom occupies the north-east alcove, and the parent's bedroom the south-east, where they are lit by reflections of morning light from 

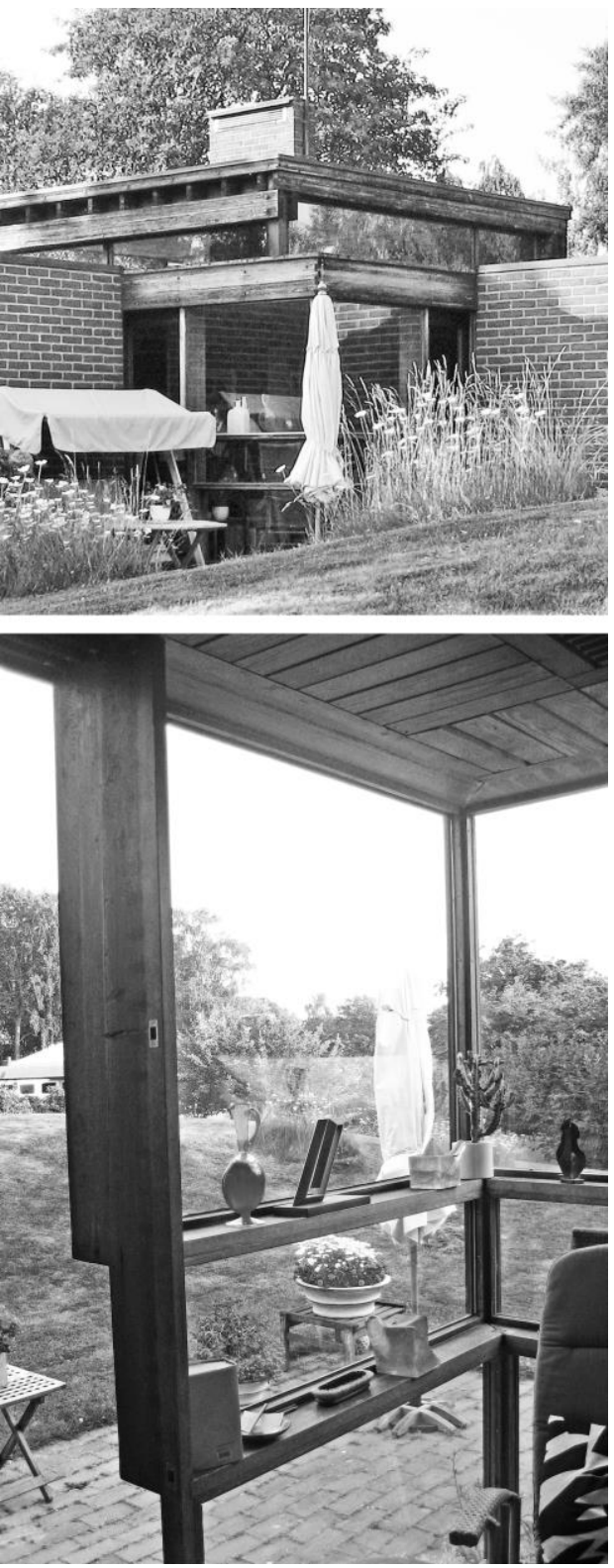

Figure 6. Villa Norrköping, Sverre Fehn, 1964. The 'eyes' of the house. Photography by Sebastian F. Licensed for reuse under creativecommons.org/ licenses/by-sa/3.0. the 'eyes' on the central core. The main living space occupies the south-west alcove, animated by late morning and midday sun, and the dining space the north-west alcove, lit by afternoon and evening light in summer. At 3pm on the winter solstice, the sun penetrates the depth of the dining space to the front door. The kitchen in the centre of the plan receives sun through the roof lantern in the morning and the evening.

The 'eyes' serve as thresholds between these spaces and the outdoors, as well as places for the children to play (Figure 6). The house is designed around circadian rhythms, and the qualities of Nordic light. According to Christian Norberg-Schulz:

Here in the North, the sun does not rise to the zenith but grazes things obliquely and dissolves in an interface of light and shadow... In the North, it is only on winter's nights that the sky becomes large, whole. Over the snow-covered earth it vaults, saturated with a peculiar "dark light."

(Norberg-Schulz 1997)

In the idea of a house open to the horizon and oriented around the compass points, Fehn references Villa Rotunda as a key precedent. But at the same time he is deeply melancholic about the loss of ontological meaning brought about by the Modernist project. While the enlightenment project and the development of astronomy took away the mystery of the horizon, for Fehn, the architecture of Modernism - opening the corners and dissolving the mass - risks the loss of mankind's place in the world entirely:

\section{In this house I met Palladio. He was tired, but all the same he} spoke:

'You have put all the utilities, bath, toilet and kitchen in the centre of the house. I made a large room of it, you know, and the dome with the opening was without glass. When I planned the house it was a challenge toward nature - rain, air, heat and cold could fill the room'.

'And the four directions', I replied.

'Oh yes, you know,' and he became smaller. 'At that time we were about to lose the horizon. You have opened the corners,' he stopped a little. 'You are on the way toward losing the globe.' (Fjeld 1983)

\section{Vanna Venturi House, $41^{\circ} \mathrm{N}$ \\ Robert Venturi (1964)}

Completed the same year as Villa Norrköping, Vanna Venturi House in Philadelphia seems to respond directly to the nostalgia Fehn expresses (Figure 7). Unlike Aalto's 'standard type' houses or Villa Norrköping, here there is no pretence of standardisation. The informality of the asymmetry of the façade, the idiosyncratic form and modest material treatment all seem to speak to a pragmatic and egalitarian promise of a home and identity of one's own.

Venturi is often associated with his one time mentor and Princeton thesis examiner, Louis Kahn. His 1950 thesis, 'Context in Architectural Composition', revealed his interests in deconstructing the dogma of Modern Movement orthodoxy early on (Rodell 2008). Nonetheless his first design for his mother's house owed more to Kahn than Aalto. According to Denise Scott Brown:

Around the school it was a big joke, Venturi is designing his mother's house again. He starts in 1958 and the first six houses are Lou Kahn groupie houses.

(Brownlee et al. 2019) 


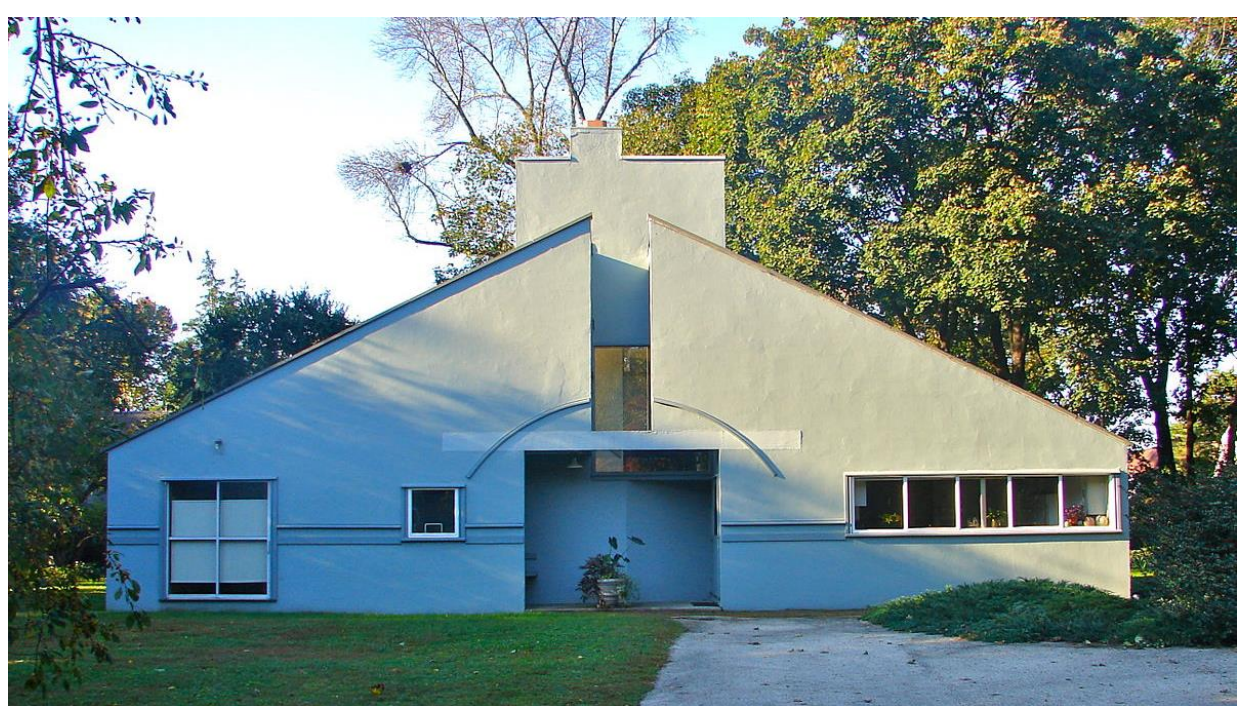

Figure 7. Vanna Venturi House, Robert Venturi, 1964. The asymmetry of the façade.

Something changed. Published two years after the completion of the house, in Complexity and Contradiction in Architecture Venturi repeatedly refers to Aalto's work to validate his manifesto, highlighting the importance of diversity in architectural form (Hirvonen 2012). Addressing Aalto, he claimed:

The best twentieth-century architects have usually rejected simplification - that is, simplicity through reduction - in order to promote complexity within the whole.

(Venturi 1966, 15)
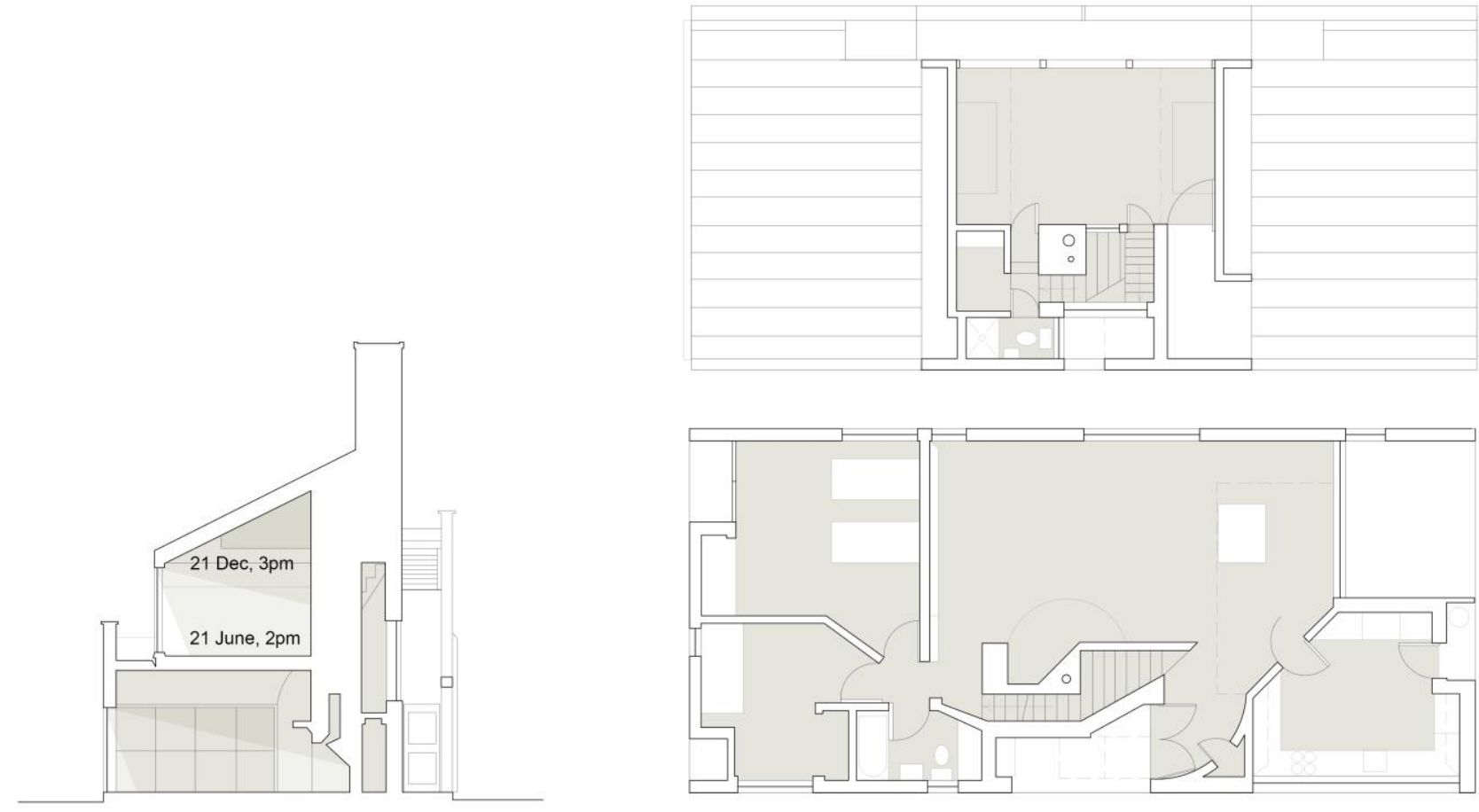

$1 \mathrm{~m}$ 5 10

Figure 8. Vanna Venturi House, Robert Venturi, 1964. Plan and section. Drawings by Sam Beckwith Flint. 
reflecting the pragmatism which was required to practice in the context of the Apartheid regime in South Africa at the time. Uytenbogaardt reflected that:

The fact that most people of any one generation live in, and use, buildings made by past generations and that most buildings today will house future generations is an important realisation. It underscores the fact that the qualities, which make buildings truly enduring, are capable of recognition beyond cultural change. This qualitative, non-programmatic dimension of architecture transcends, but still incorporates, the programme of the immediate client.

(Uytenbogaardt 2006)

Recalling Aalto's 'town-making', Kevin Fellingham describes House Uytenbogaardt (Figure 10) as a 'personal village'; 'nestled in the vegetation, but still standing proud on the hill' (Fellingham 2017). The relationship to the immediate landscape recalls the originality of much of Uytenbogaardt's earlier work, where the dialogue with the geological forms and sky of the Western Cape stands in stark contrast to the everyday functionalism of the programme, from the Sports Centre at UCT, to the Stadium at the University of the Western Cape, or Hout Bay Library.
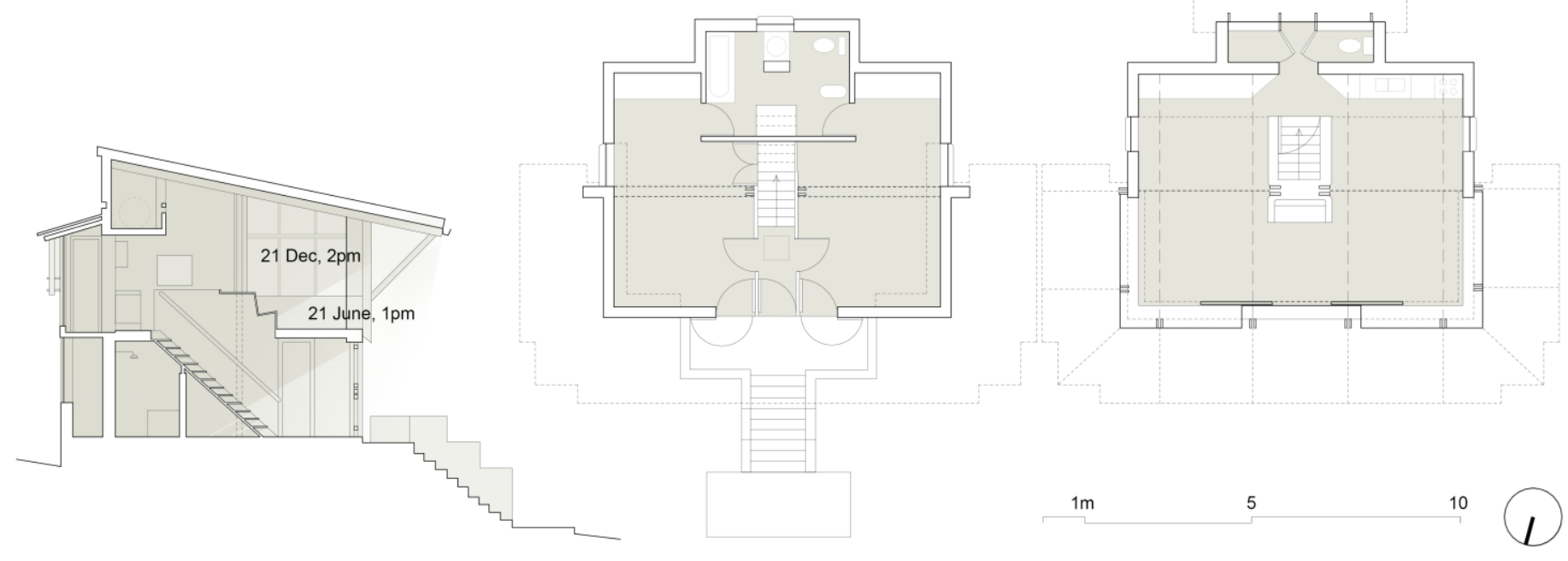

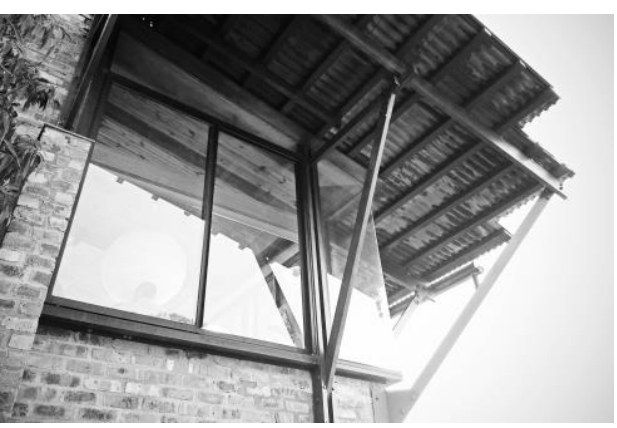

Figure 12. House Uytenbogaardt, Roelof Uyenbogaardt, 1993. The corner window. Photography by Mallix. Licensed for reuse under creativecommons.org/licenses/by$\mathrm{sa} / 2.0$.
Figure 11. House Uytenbogaardt, Roelof Uyenbogaardt, 1993. Plan and section. Drawings by Sam Beckwith Flint.

Uytenbogaardt also referenced Villa Rotunda in the design for his home. Writing shortly after its completion, his professional partner Norbert Rozendal wrote: 'This house refers to the classical tradition of a finely made object sitting in a landscape', and the 'recognition once again of the power of symmetry to organize small spaces and the ability of symmetry to empower a small building with presence' (Rozendal 1993).

The house measures only 6 by 8 metres and faces north and slightly west to the ocean. A brick shell at ground level is nestled into a hillside to the south, supporting a timber roof structure at first floor level, which extends outwards to shade the glass-lined main living space from the north sun (Figure 11). The eaves are cut back slightly in the corners to keep the 'eyes' of the house open to the horizon (Figure 12).

As with Villa Norrköping, the symmetry of the house acts as a timekeeper. The architecture is curated to the topography and the movement of the sun. In plan the house is entered centrally up an external brick stair from the north, giving access to a hallway and another stair leading up to the kitchen at the rear of the living space. The visitor then turns back towards the light and the view. 
A bench above the staircase faces the Juliet balcony looking over the ocean. In summer the eaves extend the correct distance to protect the interior from the high-angle midday sun. In winter, the sun will warm the feet of someone sitting on the bench, without producing glare at eye level.

\section{Design}

Two houses on Springvale Road, $51^{\circ} \mathrm{N}$

Author (2019)

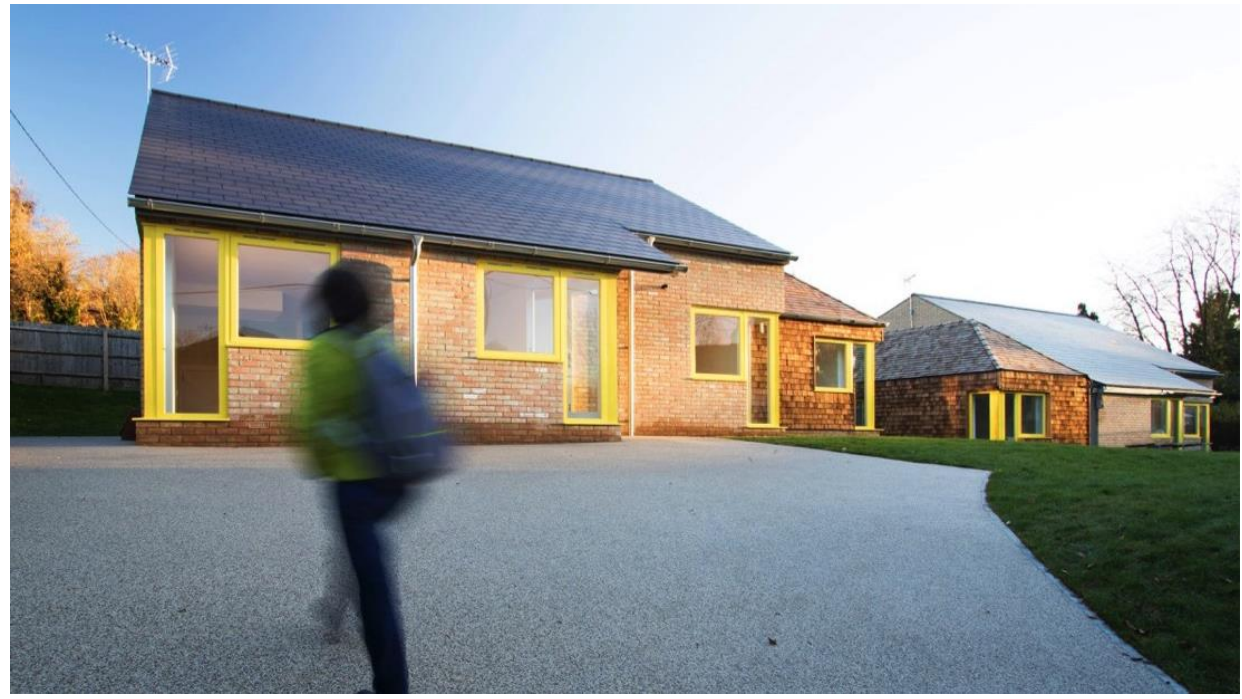

Figure 13. Two houses on Springvale Road, Author, 2019. View from Springvale Road.

Winchester is a small city 60 miles south west of London, with a population of 50,000 . Originally the walled Roman town of Venta Belgarum, the first cathedral was completed in 648AD, two centuries after the end of Roman rule. The current cathedral, completed in 1093, has the longest Gothic nave in Europe. Despite its ancient origins Winchester is growing rapidly. Its population has increased by almost $10 \%$ in the last decade, and it has also seen the biggest average rise in house prices of any city in the UK over the same period.

The site for these houses is in Headbourne Worthy, a suburb to the north of Winchester. At $51^{\circ} \mathrm{N}$ the site is equidistant in latitude between Aalto's Housing for ex-service men in Tampere and Vanna Venturi House in Philadelphia. The client inherited a mid-20 $0^{\text {th }}$ century bungalow with no level access and thermally poor construction, on a wedge shaped site facing west and sloping down towards Springvale Road. It was considered unsuitable for upgrade. Many of the neighbouring properties have been replaced in recent years with 'cookiecutter' neo-vernacular houses.

The original scheme envisaged three houses with roof pitches facing to the south and gables fronting to the street. This form was considered too 'bulky' by the local planning department, who insisted the pitches must face to the street, and only two houses would be permissible on the site (Figure 13). To reduce the massing, the planning department accepted a form composed of a larger brick section and an adjoining cedar shingle 'box'. The division is revealed internally by slot windows to front and rear and pitched soffits to the bedrooms; the material treatment (white plaster) remains consistent throughout however a 'truthful' illusion reflecting the multi-layered reality of modern airtight, insulated construction. 


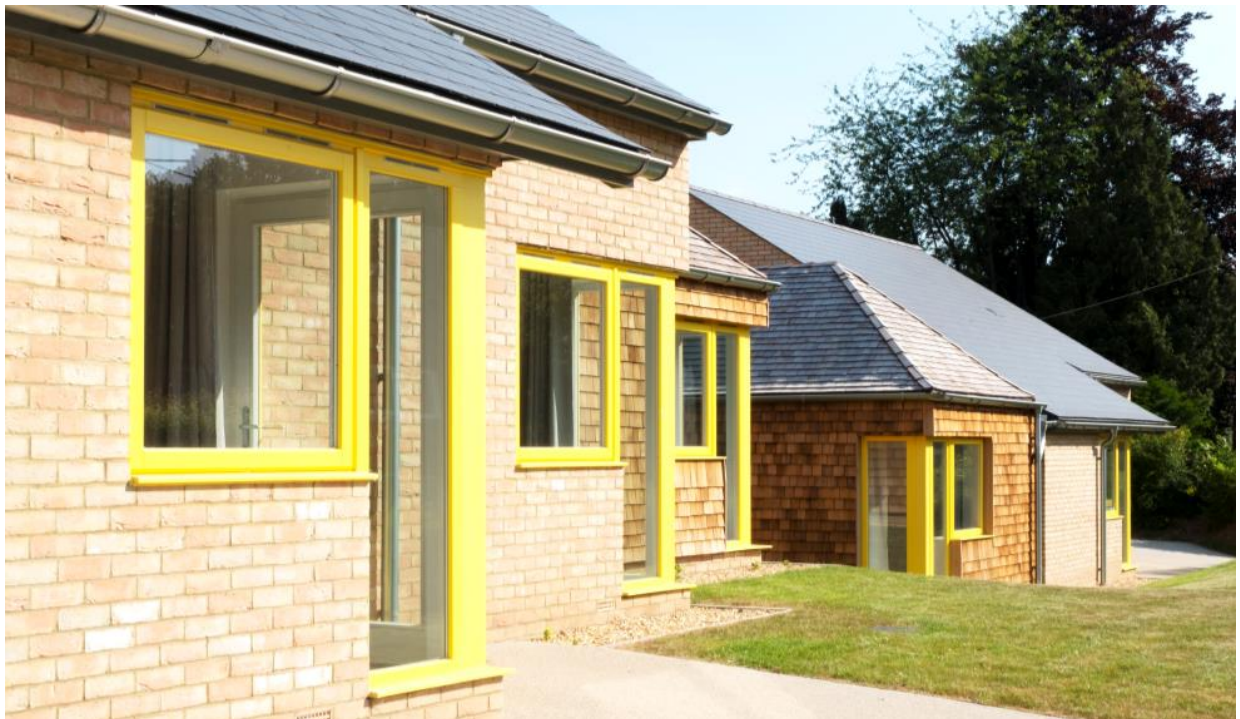

Figure 15. Two houses on Springvale Road, Author, 2019. Corner windows facing south-west.

The sequence from the road, to the door, and eventually the kitchen at the heart of each house is intended to mark the event of returning home on an otherwise constrained plot of land. From the pavement the visitor follows the side gable of either house to the retaining garden wall at the rear. Turning about 180 degrees the front door is sheltered under the projecting roof. On entry the visitor passes the stairs rising up the gable wall to the master bedroom in the pitch of the roof, and proceeds forwards into the living space, with the open kitchen to the side. Views back out to the front garden and street are animated by rays of afternoon sun from the corner windows. The circulation route continues in a pinwheel around the kitchen counter and along a short corridor accessing the remaining bedrooms and bathrooms. In Vanna Venturi House the staircase and fireplace play a key role as the pivot point in the plan; here the kitchen plays the same role, opening onto the living space and the foot of the staircase, central to life inside the house.
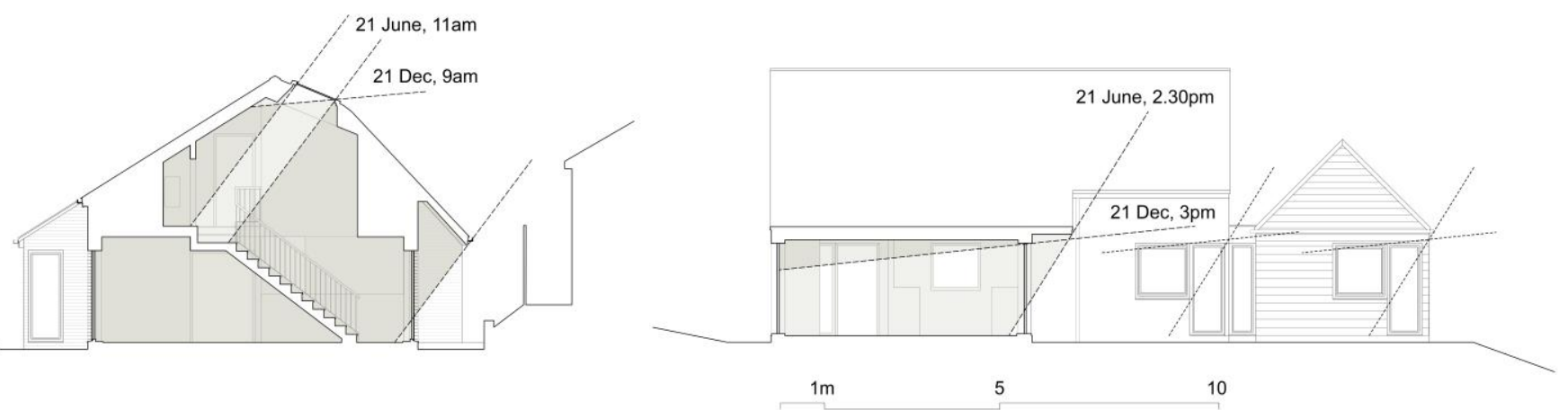

Figure 16. Two houses on Springvale Road, Author, 2019. Sections.

Most houses are intentionally designed today to reduce their energy use. However it is important to ensure that a focus on energy performance is not permitted to compromise the comfort and wellbeing of inhabitants. The 'Circadian House' describes a design philosophy that prioritises the health of occupants, recognising the role of diurnal processes in maintaining physiological and psychological wellbeing (Roy 2014).

In these houses, the orchestration of light is intended to harmonise with circadian rhythms. ${ }^{2}$ Daylight is the primary source of light throughout the day, with opportunities for views of the sky and nature in multiple directions.

2 The body responds to daylight exposure by regulating the release of different hormones: cortisol levels peak in the morning, and melatonin in the late evening. Disrupting this cycle (e.g. through light deprivation, or jet-lag), has a detrimental impact on energy levels and sleep, as well as 

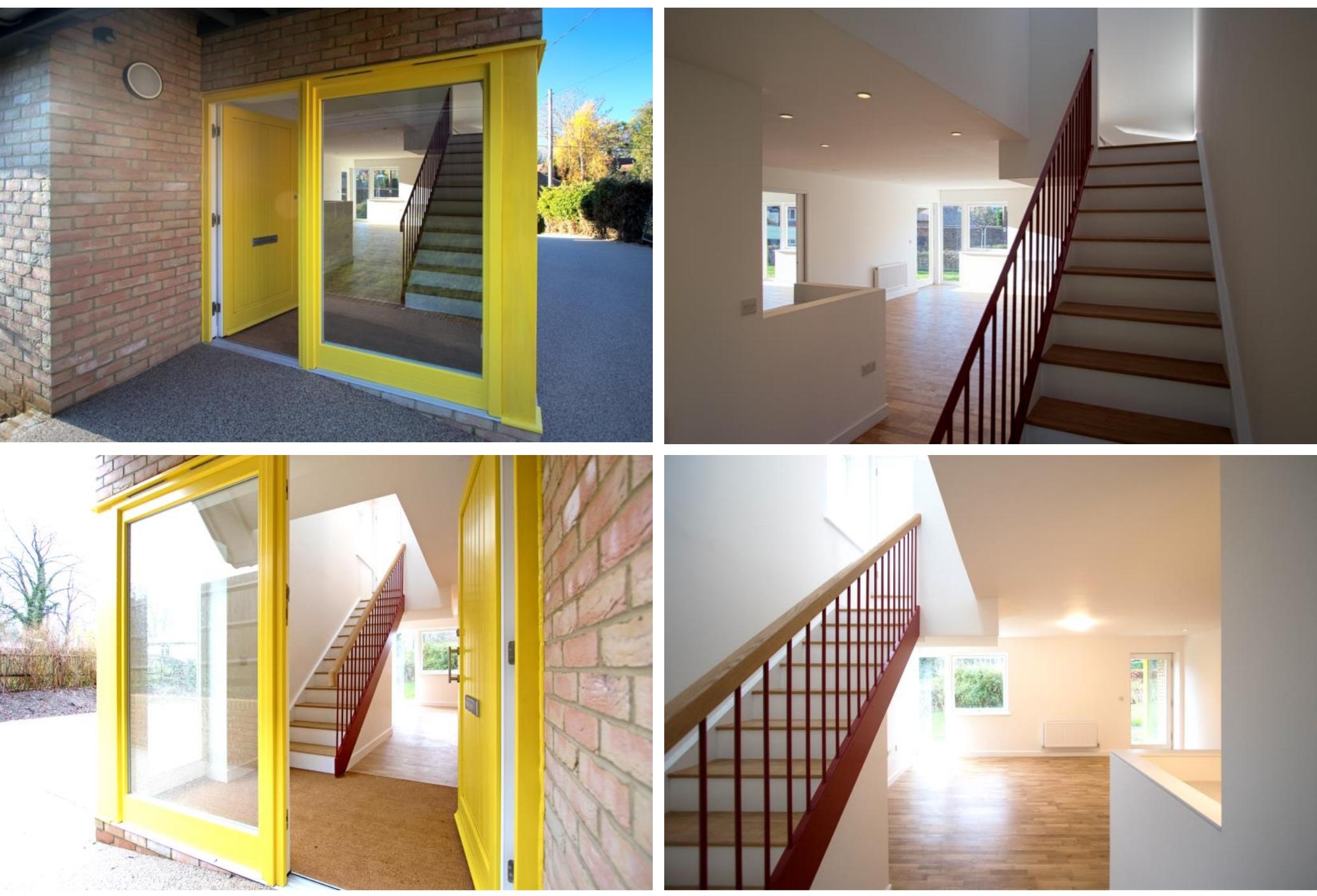

Figure 17. Two houses on Springvale Road, Author, 2019. The entrances to the rear (top: northern house; bottom: southern house).

The plan is arranged to connect spaces with the diurnal movement of the sun, increasing light levels in active spaces and allowing residents to experience the natural changes of the sunlight spectrum. The kitchen windows and the skylights over the stairs and ensuite bathroom upstairs receive morning light from the east, admitting sharply defined sun patches on clear days that track round through the morning (especially in winter), while floor-to-ceiling glazing in the 'eyes' of the living and dining spaces receive afternoon sunlight from the south and west. The windows themselves are painted warm yellow, a memory of the old house that stood on the site that also lends the houses their own distinctive identity.

The total area of glazing is greater than standard residential design in the UK, necessitating higher levels of insulation as well as solar panels in order to meet energy performance targets. The fabric of the houses is designed to meet the requirements of the UK Code for Sustainable Homes level 4 and an EPC (Energy Performance Certificate) A-rating, with a floor $u$-value of 0.1 and wall and roof $u$-values of 0.15 . Fresh air is provided through natural means, with cross ventilation of the main living space and stack ventilation through the stairwell on warm summer days. These technical requirements did not however

inducing stress (Kerkhof 1999). These impacts can be corrected (or the internal body clock reset) through restored exposure to bright light in the morning (Jewett et al. 1997). Reviewing the available research, Rea et al. have proposed that for good circadian health, exposure of the eye to light levels exceeding 1,000 lux is required for a period of at least 1-2 hours, preferably including morning light (Rea, Figueiro, and Bullough 2002). This cannot easily be achieved by artificial lighting alone. 
define the orientation, form, or spatial sequences of the design. These derive from the potential of intuitive decisions informed by the environment, and lessons from precedents borrowed and reinterpreted to the specific climatic conditions of the site. This intuitive process is not superficial, but reflects a rational approach to an infinite range of possibilities that often exist in tension with each other.

As an example, the decision to mirror the houses in elevation, taken in order to appease the neighbours to the west, who were concerned about overshadowing, had the unintended consequence of dynamically changing the mood of the entrance of each house (Figure 17). The entrance of the southern house is animated throughout the day by the movement of the sun, augmented by a high window on the landing of the staircase. The entrance of the northernmost house is cast in shadow, and the north light is cooler and more diffuse. It is surprising how two examples of substantially the same architecture in the same place can feel so different (Figure 18).
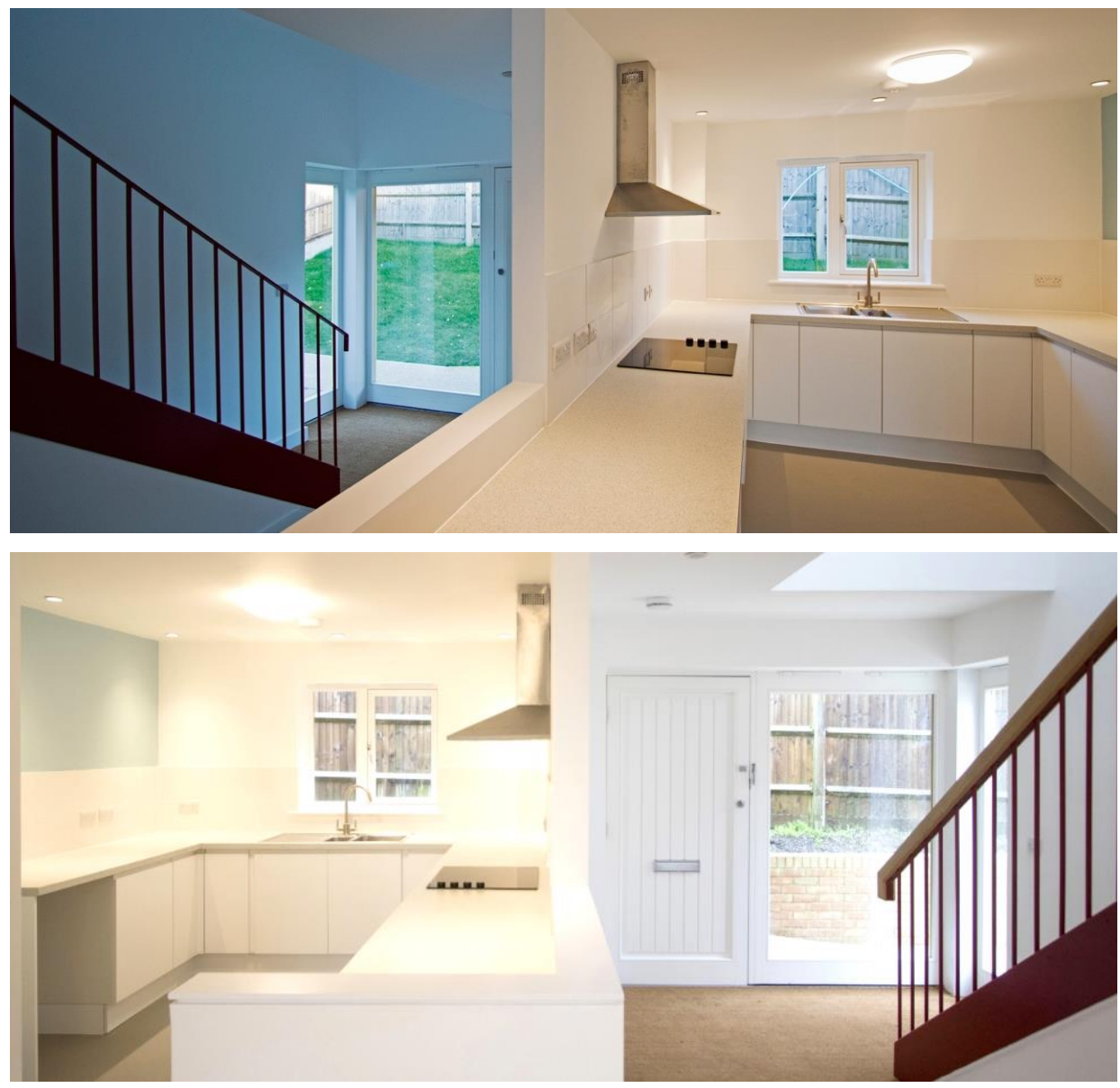

Figure 18. Two houses on Springvale Road, Author, 2019. The entrance, staircase, and kitchen (top: northern house; bottom: southern house).

\section{Conclusion}

The precedents described in this paper were all selected for the influence they had on the author's own designs. As can be seen, this influence is not primarily an aesthetic concern; instead it reveals itself in solutions to specific environmental problems - Fehn's 'eyes', for example, that in combination with the stepped plan admit sunlight into the main living spaces - or broader aspirations - the connection of indoor spaces with the diurnal movement of the sun, as demonstrated by House Uytenbogaardt, or the social role of the front door and circulation spaces in Vanna Venturi House, reflecting the life of its occupants. 
At the same time, it is impossible to recreate these inspirations at a different time and place. It is never possible to exactly reproduce another environment, as any reproduction has to exist in another location, and any other location will be different, to some degree. Nonetheless the only way that we can imagine what an environment that does not yet exist will be like is through recalling other environments that may be somewhat similar, whether in climate, scale, volume, material treatment, or spatial quality. A translation then takes place into another context. This translation can be tested and refined by experimentation and modelling, but no simulation can predict the physical world precisely - some things will always be left to chance. The question is what needs to be controlled, and how much can be left to intuition.

Environmentally, a substantial difference exists between an 'exclusive' building, where technology is allowed to permeate to the extent that the environment is controlled as a thermal and luminous constant through the tyranny of the thermostat, daylight sensor and Building Management System, and a 'selective' building, which establishes a relationship with its immediate natural environment.

In a selective building, precedents undergo a process of interpretation, assimilation and adaptation. Even in two houses built side by side, the necessities and constraints of the site dictate that the same influences will result in different outcomes. These divergences should not be viewed as shortcomings; they represent design evolution, contributing to the development of a tradition of environmentally diverse architecture from which more possibilities may emerge in future. A 'selective' characteristic shared by all of the precedents described here, through the attention paid to the size and orientation of openings and windows, is their accommodation of what Lisa Heschong describes as 'thermal delight' in architecture (Heschong 1979); a quality that depends on a dynamic relationship with climate.

Imagining different environments, rather than relying on metrics and standards, opens the door to dynamic environmental diversity, with spaces reflecting not only their immediate context but also diurnal and seasonal changes in the weather. This engagement with the outside world is full of sensorial potential, and the memory of such spaces constitutes a body of knowledge, encompassing precedent, that through practice may constitute its own authentic architectural language.

\section{References}

Aalto, Alvar. 1941. 'European Reconstruction Brings to the Fore the Most Critical Problem Facing Architecture in Our Time'. Arkkitehti 5.

Banham, Reyner. 1969. Architecture of the Well-Tempered Environment. London: Architectural Press.

Brownlee, David, Robert Venturi, Jean-Louis Cohen, Lee Ann Custer, Peter Fröhlicher, Diane Harris, Andrew Leach, et al. 2019. Complexity and Contradiction at Fifty: Studies toward an Ongoing Debate. Edited by Martino Stierli. New York: The Museum of Modern Art.

Fellingham, Kevin. 2017. The Way of All Flesh: Reflections on Entropy at Work on the Buildings of Roelof Uytenbogaardt. Cambridge: Cambridge Architectural Press.

Fjeld, Per Olaf. 1983. Sverre Fehn: The Thought of Construction. New York: Rizzoli.

Fjeld, Per Olaf, and Emily Randall Fjeld. 2019. Louis I. Kahn: The Nordic Latitudes. Fayetteville: University of Arkansas Press.

Frampton, Kenneth. 1983. 'Towards a Critical Regionalism: Six Points for an Architecture of Resistance'. In The Anti-Aesthetic: Essays on Postmodern Culture, edited by Hal Foster. New York: New Press. 
1995. Studies in Tectonic Culture: The Poetics of Construction in Nineteenth and Twentieth Century Architecture. Cambridge, Mass., London: MIT Press.

Gartner, Scott. 1990. In . Washington.

Hagan, Susannah. 2008. Digitalia: Architecture and the Digital, the Environmental and the Avant-Garde. New York: Routledge.

Hawkes, Dean. 1995. The Environmental Tradition: Studies in the Architecture of Environment. London: Taylor \& Francis.

2008. The Environmental Imagination: Technics and Poetics of the Architectural Environment. London: Routledge.

Heschong, Lisa. 1979. Thermal Delight in Architecture. Cambridge, Mass.: MIT Press.

Hirvonen, Tuomo. 2012. 'Ambiguity and Tensions in the Architecture of the Main Building of the College of Education at Jyväskylä'. In . Seinäjoki and Jyväskylä.

Jetsonen, Jari, Sirkkaliisa Jetsonen, and Markku Lahti. 2011. Alvar Aalto Houses. New York: Princeton Architectural Press.

Jewett, M. E., D. W. Rimmer, J. F. Duffy, E. B. Klerman, R. E. Kronauer, and C. A. Czeisler. 1997. 'Human Circadian Pacemaker Is Sensitive to Light throughout Subjective Day without Evidence of Transients'. The American Journal of Physiology 273 (5): 1800-1809.

Kerkhof, G. A. 1999. 'Licht En Prestatie'. In Proceedings Symposium Licht En Gezondheid. Amsterdam: SOLG.

Murray, Noëleen. 2010. 'Architectural Modernism and Apartheid Modernity in South Africa: A Critical Inquiry into the Work of Architect and Urban Designer Roelof Uytenbogaardt, 1960-2009'. University of Cape Town.

Norberg-Schulz, Christian. 1997. Nightlands: Nordic Building. Cambridge, Mass.: MIT Press.

Papkovskaia, Katia. 2011. 'The Form of Light: Sverre Fehn's Norrköping Villa'. Scroope 20: 176-89.

Pelkonen, Eeva-Liisa. 2009. 'Alvar Aalto: Planning Finland, c. 1940'. In . New York: New York University Institute of Fine Arts.

Rea, M. S, M. G. Figueiro, and J. D. Bullough. 2002. 'Circadian Photobiology: An Emerging Framework for Lighting Practice and Research'. Lighting Research \& Technology 34 (3): 177-87.

Rodell, Sam. 2008. 'The Influence of Robert Venturi on Louis Kahn'. Washington State University.

Roy, Nicolas. 2014. 'Circadian House: Principles and Guidelines for Healthy Homes'. VELUX. http://thedaylightsite.com/circadian-house-principlesand-guidelines-for-healthy-homes/.

Rozendal, Norbert. 1993. 'House Uytenbogaardt: Kommetjie, Cape'. Architecture SA, October, 14-17.

Schildt, Goran. 1986. Alvar Aalto: Decisive Years. New York: Rizzoli.

Summerson, John. 1957. 'The Case for a Theory of Modern Architecture'. RIBA Journal, June.

Uytenbogaardt, Roelof. 2006. 'An Approach to Architecture'. In Roelof Uytenbogaardt: Senza Tempo / Timeless, by Giovanni Vio. Padova: II Poligrafo.

Venturi, Robert. 1966. Complexity and Contradiction in Architecture. New York: Museum of Modern Art.

Venturi, Robert, and Denise Scott Brown. 1986. A View from the Campidoglio: Selected Essays 1953-1984. New York: Harper Collins.

Wilson, Colin St John. 1995. The Other Tradition of Modern Architecture: The Uncompleted Project. London: John Wiley \& Sons. 